\author{
A. CARRAN7.A-BENCANO* \\ J. R. ARMAS-PADRÓN** \\ $\mathrm{M}^{\mathrm{a}}$ A. LOZANO ${ }^{* * *}$ \\ * Prof. Titular de Iraumatología y Cirugía \\ Ortopédica. \\ * Prof. Titular de Anatomía-Patológica. \\ *** Médico colaborador. \\ Facultad de Medicina. Universidad \\ de Sevilla.
}

\section{Reconstrucción de lesiones osteocondrales con fibra de carbono}

\author{
Reconstruction of osteochondral \\ lesions using carbon fiber
}

\section{Resumen}

Objetivo: Estudiar a largo plazo la evolución histológica de defectos osteocondrales de la rótula de conejos tratados con fibra de carbono.

Material y Método: 18 conejos de raza gigante español, variedad parda, de ambos sexos, con un peso aproximado de 1.5 a 2 $\mathrm{Kg}$ y 18 discos Cleveland de fibra de carbono de $8 \mathrm{~mm}$ de diámetro (Medicarb®), fabricado por Leyland Medical International).

Creación de un defecto de $6 \mathrm{~mm}$. de diámetro en la superficie articular de la rótula, hasta alcanzar el tejido óseo subcondral sangrante, que fue rellenado con un disco de fibra de carbono previamente humedecido en solución salina y recortado para una adecuada adaptación al defecto.

Resultados: A los seis meses de evolución postoperatoria el defecto fue rellenado por tejido fibroso, a los nueve meses se desarrolló tejido fibrocartilaginoso y a los 12 meses los defectos estaban cubiertos por tejido cartilaginoso hialino.

Conclusiones: Demostramos la neoformación de cartilago hialino en defectos osteocondrales de rótula de conejo rellenados con fibra de carbono.

Palabras claves: Fibra de carbono. Defectos osteocondrales. Reparación.

\section{Summary}

Objetive: To study the long-term histological evolution of the repair of patellar osteochondral defects treated with carbon fiber in rabbits.

Material and methods: The study animals were 18 spanish giant rabbits, brown variety, both sexes, weight 1.5 to $2 \mathrm{~kg}$. The animals received 18 8- $\mathrm{mm}$ wide disks of Cleveland carbon fiber $\left(\right.$ Medicarb $^{\circledR}$, Leyland Medical International).

A 6-mm wide defect which reached bleeding subchondral bone tissue was created on the articular surface of the patella and filled with a carbon fiber disk previously moistened in saline solution and cut to fit the defect.

Results: Six months after surgery the defect was filled with $f$. brous tissue, 9 months after surgery fibrocartilaginous tissue developed, and 12 months after surgery the defects were covered with hyaline cartilaginous tissue.

Conclusions: We demonstrated the neoformation in rabbits of hyaline cartilage on patellar osteochondral defects filled with carbon fiber.

Key words: Carbon fiber. Osteochondral defects. Repair.

\section{Introducción}

La fibra de carbono permite la proliferación de tejido fibroso en la dirección de sus filamentos por lo que ha sido usada en la reconstrucción de tejidos fibrosos tales como ligamentos y tendones ${ }^{6}$.

El objetivo de este trabajo es estudiar a largo plazo la evolución histológica de defectos osteocondrales

\section{Correspondencia:}

Prof. Dr. A. CARRANZA-BENCANO. C/ Santa Clara, 16-1ㅁ-D. 41002 Sevilla. amplios y profundos de la superficie articular de la rótula de conejos tratados con fibra de carbono.

\section{Material y métodos}

Se han utilizado 18 conejos de raza gigante español, variedad parda, de ambos sexos, con un peso aproximado de 1.5 a $2 \mathrm{Kg}$ y 18 discos Cleveland de fibra de carbono de $8 \mathrm{~mm}$ de diámetro (Medicarb® ${ }^{\circledR}$, fabricado por Leyland Medical International LTD).

La cirugía experimental consistió en incisión pararotuliana interna para poder luxar externamente la 


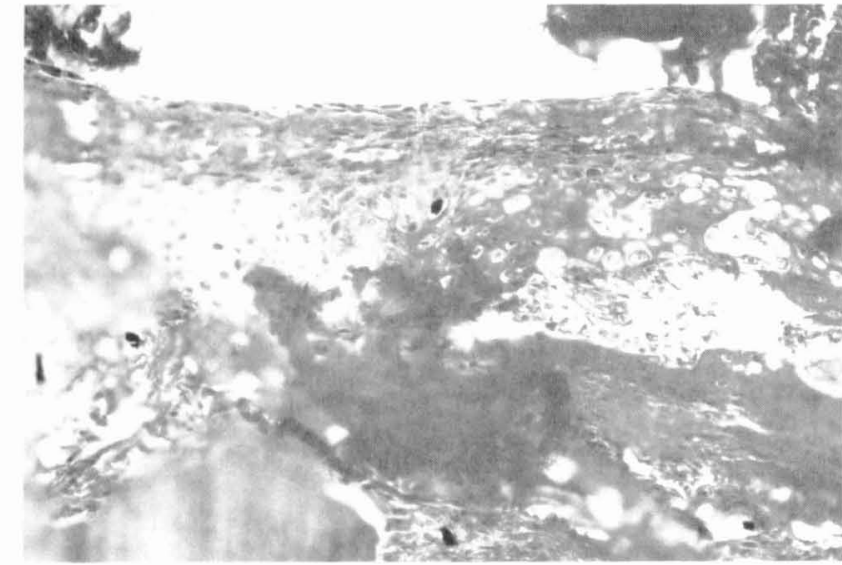

FIG. 1.-Defecto relleno con fibra de carbono a los seis meses de evolución. Restos de fibra de carbono en la base de la lesión con formación de tejido óseo y fibroso. Disposición paralela de tejido fibroso en superficie (H-E, 500 x). rótula, exponer el cartílago articular y realizar la extirpación del mismo, con una broca de $6 \mathrm{~mm}$ de diámetro, hasta alcanzar el tejido óseo subcondral sangrante. El área rotuliana denudada fue rellenada con un disco de fibra de carbono previamente humedecido en solución salina y recortado para una adecuada adaptación al defecto creado.

En el postoperatorio la extremidad fue inmovilizada con escayola durante una semana, manteniendo la rodilla en flexión de $30^{\circ}$, permitiendo a los animales desplazarse libremente dentro de sus jaulas.

Los animales fueron sacrificados en grupos de seis, por inyección de $30 \mathrm{mg}$ de Thiobarbital a los seis meses, nueve meses y 12 meses ulteriores a la intervención. Tras el sacrificio se efectuó la extracción de la rótula operada, para fijación en formaldehido al 10\%, decalcificación en ácido nítrico, procesado en parafina y obtención de cortes de cinco micras para su tinción en hematoxilina-eosina.

\section{Resultados}

Seis meses después de la operación: En el área profunda de los defectos rellenados con fibra de carbono se apreciaban restos de la misma, con formación de tejido óseo y sobre todo de tejido fibroso, con reacción granulomatosa a cuerpo extraño con células gigantes multinucleadas. En el área superficial el tejido fibroso se disponía paralelamente a la superficie articular con buena integración de dicho tejido fibroso en ambos extremos con el cartílago articular adyacente, que presentaba abundancia de grupos isógenos (Fig 1).

Nueve meses después de la operación: Al igual que en el grupo anterior el fondo de las lesiones mostraba la presencia de la fibra de carbono con formación de tejido óseo y sobre todo de tejido fibroso. En superficie

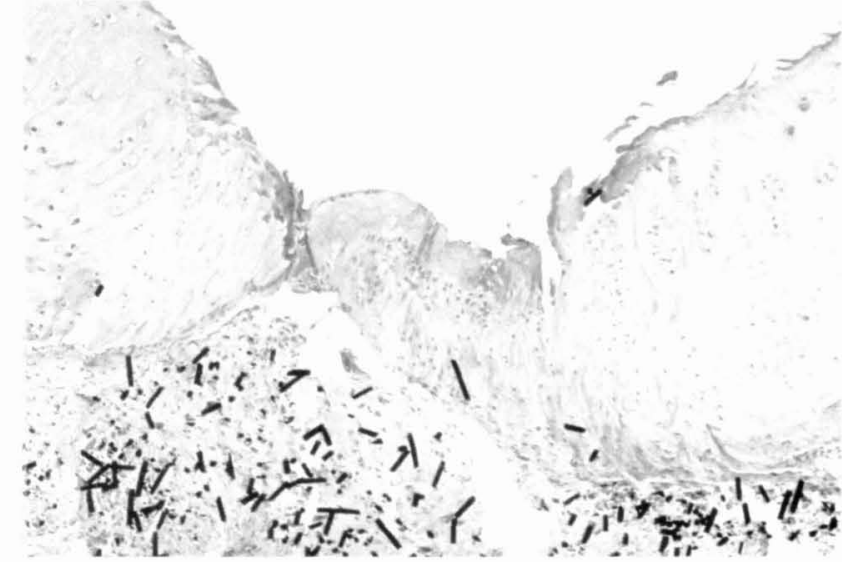

FIG. 2.-Defecto relleno con fibra de carbono a los nueve meses de evolución. Fibre de carbono con tejido óseo y fibroso en la base de la lesión y fibrocartílago y cartílago hialino en superficie (H-E, $250 \mathrm{x}$ ).

se observaba tejido cartilaginoso y fibrocartilaginoso, con buena integración en ambos extremos con el cartílago adyacente, que enseñaba abundancia de grupos isógenos (Fig. 2)

Doce meses después de la operación: Los defectos rellenados con fibra de carbono seguían mostrando dichas fibras en el fondo de las lesiones con desarrollo de tejido óseo y fibroso. Pero en superficie se observaba la formación de cartílago hialino exclusivamente, aunque en los cortes centrales presentaba una pequeña zona central de tejido fibroso en íntima relación con las fibras de carbono subyacentes. La superficie articular era cóncava y regular con un grosor normal del cartílago hialino neoformado en la lesión, integrado en sus dos extremos con el cartílago adyacente que mostraba una celularidad normal (Fig. 3).

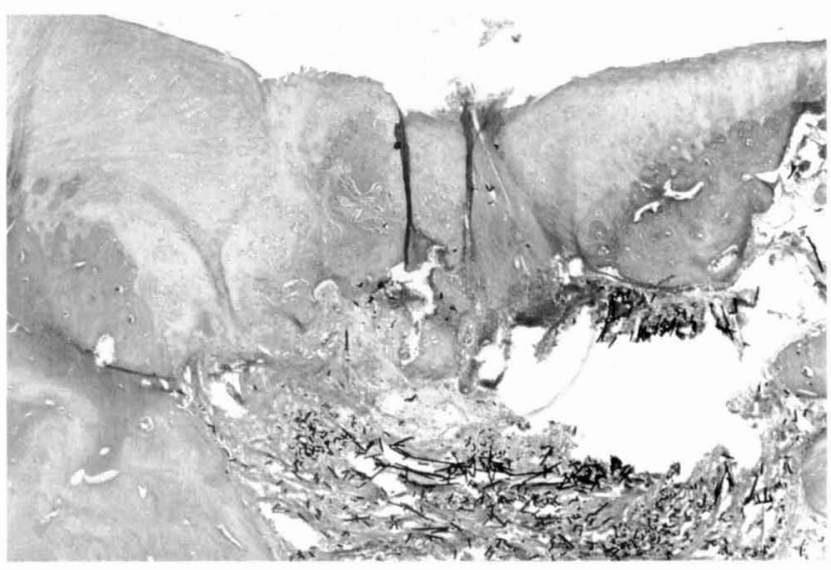

FIG. 3.-Defecto relleno con fibra de carbono a los 12 meses de evolución. Fondo de la lesión con fibra de carbono recubierta por cartílago hialino (H-E, 100 x). 


\section{Discusión}

Dada la limitada capacidad de reparación de las lesiones profundas y amplias del cartílago hialino articular ${ }^{1,3-5,7,8,11,12,15}$ y su tendencia a largo plazo a evolucionar hacia la osteoartrosis 5,7 , hemos utilizado un modelo experimental de lesión osteoarticular del que destacamos el hecho de que los defectos creados presentaban $6 \mathrm{~mm}$ de diámetro, que comprende más del $75 \%$ de la superficie de la rotula del conejo, mientras que defectos de pequeño tamaño ha sido publicado que sufren reparación espontánea, sobre todo bajo movimiento pasivo continuo ${ }^{13}$.

En estudios previos de nuestro laboratorio hemos comprobado que injertos libres de periostio ${ }^{14}$ y pericondrio $^{2}$ tienen capacidad condrogénica para reparar defectos similares de la superficie articular de la rótula de conejo. Como complemento de esta línea planificamos este trabajo de investigación con fibra de carbono basándonos en estudios previos de Minns ${ }^{9,10} \mathrm{y}$ pensando estudiar fundamentalmente el desarrollo de tejido fibroso de reparación (como comprobamos en el grupo de animales sacrificados a los seis meses) pero hemos demostrado la evolución de este tejido fibroso a fibrocartilaginoso a los nueve meses y la formación de cartílago hialino en los animales sacrificados al año de la intervención.

En base a estos resultados se puede especular que la formación de cartílago hialino debe estar influenciado por factores biactivos derivados del fluido sinovial, aunque esta teoría no puede ser verificada en este trabajo al ser realizado sin marcaje celular. Pensamos que podría ser una línea de investigación sugerente y con potencial aplicabilidad en la regeneración articular.

\section{Bibliografía}

1. Basset CAL. Current concepts of bone formation. J Bone Joint Surg 1962;44-A:1217-44.
2. Ballesteros-Vázquez P, Carranza Bencano A, Armas-Padrón JR, Sáenz-López F. Reparación del cartílago articular con injerto libre de pericondrio. Estudio experimental. Rev Esp Cir Osteoart 1994;29:57-65.

3. Convery FR, Akenson WH, Keown GH. The repair of large osteochondral defects. An experimental study in horses. Clin Orthop 1972;82:253-63.

4. Coutts RD, Woo SL, Amiel D, Von Schroeder IP, Kwan MK. Rib perichondrial autografts in full-thickness articular cartilage defects in rabbits. Clin Orthop 1992;275:263-73.

5. Furukawa T, Eyre DR, Koide S, Glimcher MJ. Biochemical studies on repair cartilage resurfacing experimental defects in the rabbit knee. J Bone Joint Surg 1980;62 A:79-89.

6. Jenkins DHR, Forster IW, McKibbin B, Ralis ZA. Induction of tendon and ligament formation by carbon implants. J Bone Joint Surg 1977;59-13:53-57.

7. Kim HKW, Moran ME, Salter RB. The potential for regeneration of articular cartilage in defects created by chondral shaving and subchondral abrasion. An experimental investigation in rabbits. J Bone Joint Surg 1991;73-A:1301-15.

8. Iwasaki $M$, Nakahara $H$, Nakata $K$, Nakase $T$, Kimura $\mathrm{T}$, Ono $\mathrm{K}$. Regulation of proliferation and osteochondrogenic differentiation of peiosteum-derived cells by Transforming Growth Factor B and Basic Fibroblast Growth Factor. J Bone Joint Surg 1995;77-A:543-54.

9. Minns RJ, Muckle DS. Mechanical and histological response of carbon fibre pads implanted in the rabbit patella. Biomaterials 1989:10:273-6.

10. Minns RJ, Muckle DS, Betts JA. Biological resurfacing using carbon fibre. Orthopaedics Int 1993;5:414-24.

11. Mitchell N, Shepard NC. The resurfacing of adult. Rabbit articular cartilage by multiple perforation through the subcondral bone. J Bone Joint Surg 1976;58-A:230-3.

12. Nakahara H, Bruder SP, Haynesworth SE, Hotecek JJ, Baber MA, Goldberg VM, Caplan AT. Bone and cartilage formation in diffusion chambers by subcultured cells derived from the periostum. Bone 1990;11:181-8.

13. O'Driscoll SW, Salter RB. The induction of neochondrogenesis in free intra-articular periosteal autografts under the influence of continous passive motion. An experimental investigation in the rabbit. J Bone Joint Surg 1984;66-A: 1248-57

14. Pérez-Tinao M, Carranza-Bencano A, Armas-Padrón JR. Capacidad condrogénica de injertos libres de periostio en la reparación de defectos del cartílago articular. Estudio experimental en conejos. Rev Esp Cir Osteoart 1996;31:5-13.

15. Uichida A, Kikuchi T, Shimomura Y. Osteogenic capacity of cultured human periosteal. Actha Orthop Scand 1988;59: 29-33. 